\title{
Cardiac magnetic resonance imaging parameters as surrogate endpoints in clinical trials of acute myocardial infarction
}

\author{
Steffen Desch ${ }^{1 *}$, Ingo Eitel', Suzanne de Waha', Georg Fuernau', Philipp Lurz ${ }^{1}$, Matthias Gutberlet ${ }^{2}$, \\ Gerhard Schuler $^{1}$ and Holger Thiele ${ }^{1}$
}

\begin{abstract}
Cardiac magnetic resonance (CMR) offers a variety of parameters potentially suited as surrogate endpoints in clinical trials of acute myocardial infarction such as infarct size, myocardial salvage, microvascular obstruction or left ventricular volumes and ejection fraction. The present article reviews each of these parameters with regard to the pathophysiological basis, practical aspects, validity, reliability and its relative value (strengths and limitations) as compared to competitive modalities. Randomized controlled trials of acute myocardial infarction which have used CMR parameters as a primary endpoint are presented.
\end{abstract}

Keywords: Myocardial infarction, surrogate endpoints, cardiac magnetic resonance imaging, validity, reliability, clinical trial

\section{Introduction}

Reductions of mortality and morbidity are the ultimate treatment goals in ST-elevation myocardial infarction (STEMI). Therefore, primary endpoints in clinical studies of new therapeutic interventions are ideally events relevant to patients such as death, reinfarction or new symptoms of heart failure. However, studies with clinical endpoints are associated with several shortcomings. The incidence of the event of interest (e.g. death following myocardial infarction) is increasingly low during shortor medium-term follow-up given the advances in treatment. Furthermore, some events might not be linked to atherosclerotic disease resulting in low sensitivity. As a consequence, large sample sizes and long follow-up periods are required absorbing time and financial resources. Missing data and noncompliance are also more likely in longer-lasting studies [1].

Surrogate endpoints can overcome some of these problems allowing for a reduction in sample size and follow-up duration as well as studying pathophysiological mechanisms of disease thereby improving trial efficiency.

\footnotetext{
* Correspondence: stdesch@web.de

${ }^{1}$ University of Leipzig - Heart Center, Department of Internal Medicine/

Cardiology, Leipzig, Germany

Full list of author information is available at the end of the article
}

Surrogate endpoints are alternative endpoints "used as a substitute for a clinically meaningful endpoint that measures directly how a patient feels, functions or survives. Changes induced by a therapy on a surrogate endpoint are expected to reflect changes in a clinically meaningful endpoint" [2]. As compared to true clinical endpoints, surrogate endpoints should ideally be easy to measure and should occur more frequently and earlier in the course of the disease.

Cardiac magnetic resonance (CMR) imaging offers a variety of parameters potentially suited as surrogate endpoints and is increasingly being used in clinical trials of STEMI. Following a short conceptual overview of surrogate endpoints, we describe several of these CMR parameters and their value in infarction trials.

\section{Surrogate Endpoints \\ Definition}

According to a widely known definition published by a working group of the National Institutes of Health, a surrogate endpoint is "a biomarker that is intended to substitute for a clinical endpoint. A surrogate endpoint is expected to predict clinical benefit (or harm or lack of benefit or harm) based on epidemiologic, therapeutic, pathophysiologic, or other scientific evidence." [3]. 
A biological marker is defined as "a characteristic that is objectively measured and evaluated as an indicator of normal biological processes, pathogenetic processes, or pharmacologic responses to a therapeutic intervention" [3]. Surrogate endpoints are thus a subset of biological markers.

\section{Validity}

According to the "International Conference on Harmonisation ( $\mathrm{ICH})$ " the strength of the evidence for surrogacy depends upon (i) the biological plausibility of the relationship, (ii) the demonstration in epidemiological studies of the prognostic value of the surrogate for the clinical outcome and (iii) evidence from clinical trials that treatment effects on the surrogate correspond to effects on the clinical outcome [4]. The simple biological association between surrogate and clinical outcome is therefore not sufficient for a marker to qualify as a surrogate endpoint.

\section{Reliability}

Apart from validity, surrogate markers must also prove a high degree of reliability. Reliability refers to the consistency of measurements with only minimal variability. Reliability may be estimated through a variety of methods such as intraobserver repeatability (degree of variability if measurements of the surrogate are repeated under identical circumstances by the same person) or interobserver repeatability (degree of variability when measurements are repeated by a different observer). Reliability does not imply validity.

\section{Limitations of Surrogate Endpoints}

The use of surrogate endpoints is controversial. Most importantly, surrogate endpoints are often criticized for poor validity or even a complete lack of validation studies. Another point of criticism of surrogate endpoints relates to the safety of therapeutic interventions. Since surrogate endpoint studies usually enroll fewer patients than trials with clinical endpoints (indeed this is considered one of the essential advantages of surrogate trials), there is a substantial risk to underdiagnose rare adverse events.

\section{Cardiac Magnetic Resonance Imaging Parameters Potentially Suited as Surrogate Endpoints Infarct Size}

Basic Description Myocardial infarction can be visualised and quantified using inversion recovery imaging 10 to 15 minutes after intravenous administration of gadolinium contrast (late enhancement imaging). With correct settings, the area of infarcted myocardium appears bright whereas normal myocardium appears black (Figure 1). Experimental models have shown excellent agreement between the size and shape of late contrast enhancement in CMR and areas of myocardial necrosis or scar by histopathology $[5,6]$.

In the first days following myocardial infarction, infarct volume is usually greatest possibly in part due to marked

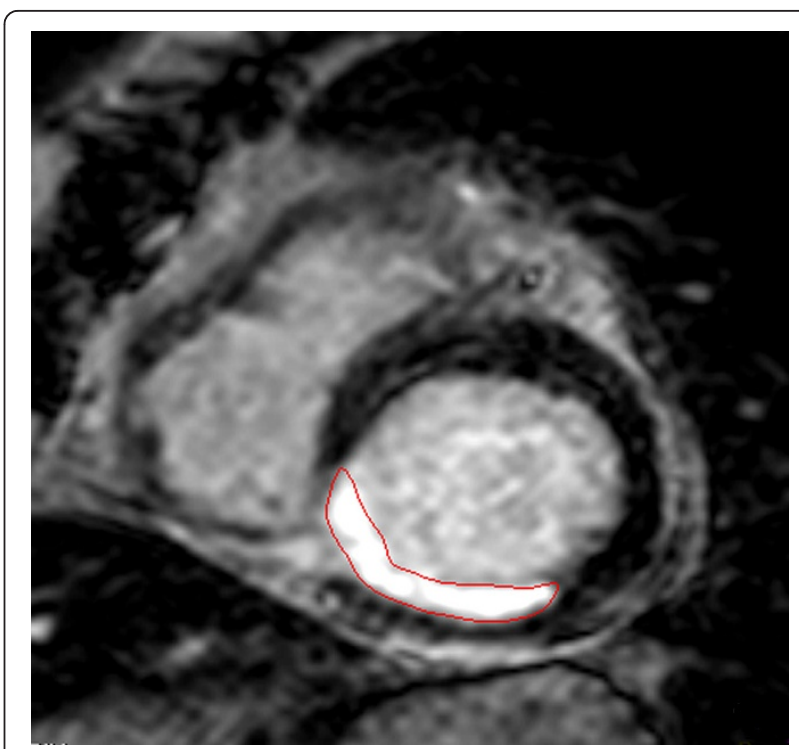

Figure 1 Late enhancement CMR imaging showing infarcted myocardium (red contours) in a patient with inferior/ inferoseptal STEMI due to occluded right coronary artery

tissue swelling $[7,8]$. As necrotic tissue is replaced by scar, infarct size decreases over the course of several weeks (most pronounced in the first week) $[7,8]$. These remodelling processes are usually completed after 6 to 8 weeks and infarct size is stable thereafter $[7,8]$. The dynamic evolution of infarct volume following infarction must be taken into account when using infarct size as a surrogate endpoint in clinical trials. When measuring infarct size in the first days or weeks after infarction, it is important to adhere to a consistent time interval between infarction and CMR image acquisition across all patients whenever possible. Otherwise infarct size variability may be explained simply by the differences in timing of CMR assessment following infarction. Although the time from symptom onset to image acquisition could be used to define the interval, time from revascularization to image acquisition might be more appropriate since reperfusion injury can exert a major influence on infarct size (and subsequent myocardial salvage) and microvascular obstruction. With the latter approach, it stands to reason that the variability of differences in the time from symptom onset to reperfusion is a potential confounder and study sample size must be adapted accordingly. In the chronic phase the imaging time frame can be chosen more liberally. Advantages of performing CMR assessment early after infarction include the concomitant assessment of microvascular obstruction or the area at risk. In general, the decision when to measure infarct size must be based on trial specifics. A limitation of infarct size assessment by late enhancement CMR is the lack of standardized protocols for primary image acquisition 
(e.g. with regards to pulse sequences or dose of contrast agent). Recommendations for standardization have recently been published [9]. Newer phase-sensitive inversion recovery sequences are able to achieve a more consistent contrast between infarcted and normal myocardium which in turn might influence measurement variability in image analysis [10].

It should be noted that there are yet no data on the reliability of infarct size measurements between scanners from different vendors. This, however, would be a prerequisite for infarct size to qualify as a reliable endpoint in multicenter trials with a variety of scanners.

Image Analysis For research purposes, quantitative analysis of infarct volume is best performed by delineating infarct borders in a stack of short-axis slices covering the whole ventricle. Infarct size can be expressed as absolute mass or percent of left ventricular mass (mass [grams] = volume $[\mathrm{mL}] \times$ myocardial density $[1.05$ grams $/ \mathrm{mL}])[11]$.

Delineation of the infarct region can be performed by manual planimetry based on visual assessment of infarct borders or by using semiautomatic analysis software. Although manual tracing might be partially subjective, it has been used extensively by many CMR centers [12-14]. In an attempt to overcome the subjective nature of visual assessment and manual planimetry, several semiautomatic methods have been proposed [15]. Semiautomatic methods are based on enhanced signal intensity of the infarcted area as compared to normal myocardium. Infarcted myocardium can be defined by exceeding a threshold value of signal intensity as compared to a reference region located in healthy myocardium. Initial ex vivo studies suggested an image intensity threshold of 2 to 3 standard deviations above remote normal myocardium for infarct characterization $[5,16]$. However, spatial resolution for in vivo examinations is much lower mainly due to cardiac motion. Therefore, a threshold value of 5 standard deviations might be more appropriate in the clinical setting [12]. However, there is currently no consensus which threshold is best/preferable for infarct size assessment. In principle, choosing a lower threshold value such as 2 standard deviations will likely include the border zone of the infarct possibly leading to overestimation of infarct size. With a higher cut-off value such as 5 standard deviations only areas with high signal intensities like the core will be characterized as infarcted. Naturally, infarct characterization is also highly dependent on the choice (signal intensity) of the remote region. Some of these problems can be avoided using the full-width at half-maximum method. A region in the central infarct core is chosen as reference [17]. Myocardium displaying a signal intensity of at least $50 \%$ of the reference region will be marked as infarcted. Full-width at half-maximum might be inaccurate in homogeneously gray infarcts without a clear hyperintense core or in infarcts with a patchy necrosis pattern [15]. Of note, the newer semiautomatic methods require a certain degree of subjective input as well. Endocardial and epicardial borders must still be drawn manually. This includes the endocardial infarct border which can comprise up to $50 \%$ of the infarct perimeter [15]. Furthermore, artefacts and obvious misclassifications of healthy tissue as myocardial infarction can be manually corrected. Semiautomatic methods have so far been tested in few patients only [15]. Flett et al. compared the reproducibility of 7 late enhancement quantification techniques in 20 patients with acute myocardial infarction: Manual quantification, thresholding by 2, 3, 4, 5 , or 6 standard deviations above remote myocardium, and the full-width at half-maximum technique [18]. The full-width at half-maximum technique was the most reproducible compared with any other method. Semiautomatic methods are constantly being refined and more complex image analysis algorithms will likely lead to further improvements [19-21].

Apart from quantitative analysis of infarct volume as described above, late enhancement imaging can also be used to measure the extent of infarct transmurality which provides additional information in predicting improvement in contractile function after myocardial infarction [22].

Validity and reliability When applying the above-mentioned ICH criteria, validity for infarct size as a surrogate endpoint is relatively high: The capacity of infarct size to predict various clinical endpoints has been demonstrated in several epidemiological studies [23,24]. It has been reported that infarct size measurement by CMR is a stronger predictor of outcome than left ventricular function and volumes [24]. Also, the relationship between the surrogate infarct size and clinical outcome seems biologically plausible. However, evidence from clinical trials that treatment effects on the surrogate also correspond to effects on the clinical outcome is more difficult to establish. An example of a sequential approach with a positive surrogate endpoint study subsequently triggering a trial with true clinical endpoints has recently been presented $[25,26]$. In a randomized controlled trial of 144 patients with STEMI, intracoronary bolus administration of abciximab led to significant reductions in CMR infarct size as compared to standard intravenous bolus application (presumably through higher local drug concentrations that can be achieved through the intracoronary route) [25]. Based on these favorable effects on a surrogate endpoint, a large study (1912 patients) with a primary clinical endpoint of mortality, reinfarction and new heart failure symptoms has been initiated [26].

For manual tracing, infarct size measurement shows excellent interobserver reliability in the acute and chronic setting [14].

Comparison to alternative methods Infarct size assessment by CMR offers several advantages over alternative 
methods. Owing to its high spatial resolution, it is possible to detect and quantify small endocardial infarcts which are often missed by single photon emission computed tomography (SPECT) imaging $[6,27]$. Given the high efficacy of modern reperfusion therapy with infarct size $\leq 10 \%$ of left ventricular mass in almost one half of patients, this aspect is of great importance [28]. It must be emphasized that the ability of CMR to detect smaller infarcts and therefore potentially smaller differences in infarct size between treatment groups does not necessarily translate into a reduced sample size for a given trial unless the standard deviation of measurements is also reduced. Apart from alpha (usually set at 0.05) and the desired power (usually set at 0.80 or 0.90 ), sample size for a standard two-arm superiority trial is dependent on the expected difference between treatment arms (the smaller the difference to be detected, the more patients will have to be enrolled) and its standard deviation. Patient-to-patient variability (reflected by the standard deviation) is naturally dependent on built-in differences in infarct size, but also on extraneous variability such as inconsistent data acquisition or image analysis technique. Thus far, the (limited) literature does not support any reduction in the overall standard deviation of CMR infarct size measurements compared to SPECT [29].

Furthermore, SPECT imaging is associated with exposure to ionizing radiation which might become especially relevant in longitudinal studies with multiple assessments of myocardial morphology and function. It should, however, be kept in mind that most patients with myocardial infarction are relatively old and longevity will likely be limited by cardiovascular morbidity rather than the risk imposed by additional radiation.

Infarct size may also be quantified through cardiac enzyme analysis by estimating the cumulative "area under the curve" or peak enzyme release in serial measurements [30]. However, CMR offers the advantage of obtaining additional parameters such as left ventricular volumes, ejection fraction, microvascular obstruction, myocardial salvage or infarct-associated complications. This aspect might be especially important in interpreting study results in their pathophysiological context and generating hypotheses for mechanisms of action for the therapeutic intervention under examination. In contrast to enzymatic analysis, CMR can also be used for serial assessments to evaluate postinfarction remodelling.

\section{Myocardial Salvage}

Basic Description Myocardial salvage, which is defined as salvaged tissue following reperfusion therapy, holds promise as a surrogate endpoint. The area of high signal (edematous myocardium) on T2-weighted CMR imaging likely reflects the area at risk in acute myocardial infarction (Figure 2a) [31]. By comparing the area at risk in $\mathrm{T} 2$-weighted and final infarct size in late enhancement

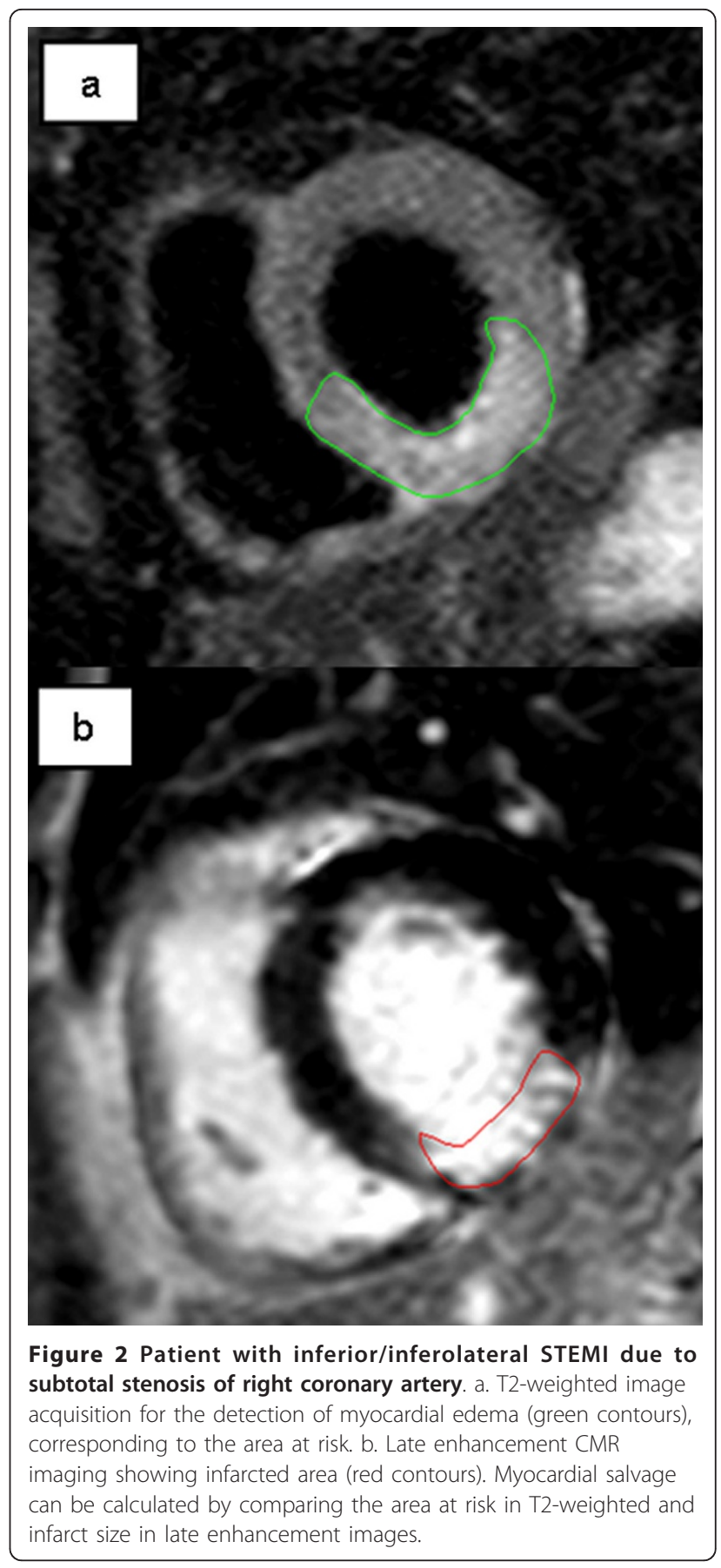

CMR images, the proportion of myocardial salvage can be assessed retrospectively (Figure $2 \mathrm{a}+\mathrm{b}$ ) [32]. In myocardial salvage assessment, reduction of infarct size can also be considered the main biological target, however with a „built-in” adjustment for the area at risk. Therefore, many of the characteristics for infarct size mentioned above are also true for the assessment of myocardial salvage. Theoretically, there are advantages of measuring salvaged myocardium over infarct size as 
an indicator of therapeutic efficacy in clinical trials. To illustrate this point consider a two-arm randomized trial of a novel therapeutic intervention with baseline imbalances of anterior and non-anterior infarctions between groups and subsequent differences in the area at risk. Since the area at risk can by itself explain over $50 \%$ of infarct size variability, it is likely that this constellation leads to differences in final infarct size between groups independent of the therapeutic intervention under examination [33]. Small differences in the area at risk may result in significant variation of infarct size, underscoring the fact that most of infarct size variability is due to the extent of the myocardium at risk [33,34]. Therefore, measuring only infarct size might impose a potential bias and myocardial salvage may be a better surrogate endpoint than infarct size. This is especially true in non-randomized study designs or smaller randomized trials where imbalances of baseline characteristics between treatment groups are frequent. In large randomized trials baseline imbalances are less likely, however at the cost of increased sample size.

As for infarct size, there is a lack of standardization with regard to image acquisition and analysis. Also, in the setting of multicenter trials, the potential variability of infarct size measurements between scanners from different vendors should be taken into account. Currently, most of the clinical experience in visualising myocardial edema has been obtained using inversion recovery turbo spin echo (TSE) sequences with suppression pulses for both fat and blood. Although these sequences provide useful images in most clinical cases, they have inherent limitations such as artefact susceptibility, variability in signal intensity if phased array coils are used and low contrast-to-noise ratio [35]. Slow flowing blood in particular near dyskinetic segments in the apex and between trabeculae may not be suppressed sufficiently. The corresponding high signal can, therefore, erroneously be included in the delineation of the area at risk [35]. One method to reduce this in clinical practice is to compare T2-weighted images of the same cardiac phase side-byside with cine images to verify wall thickness. Newer sequences might account for several of these limitations. Specifically, a T2-prepared steady state free precession (SSFP) technique has been studied as an alternative to conventional T2-weighted TSE imaging [36]. In a trial of 31 patients with myocardial infarction (22 acute, 9 chronic) T2-prepared SSFP provided images with fewer artefacts and better diagnostic accuracy compared to T2weighted TSE imaging albeit at reduced signal-to-noise ratio [36]. A hybrid method of the aforementioned SSFP sequence and conventional T2-weighted TSE imaging has also been presented combining the advantages of SSFP imaging with the higher signal-to-noise and contrast-to-noise ratio of T2-weighted TSE imaging [37]. An alternative approach to T2-weighted imaging using signal intensity as a surrogate for T2 prolongation is the direct determination of myocardial $\mathrm{T} 2$ relaxation times. Thereby, several limitations associated with conventional T2-weighted imaging can be addressed, resulting in a potentially more reliable method for the detection of myocardial edema and the area at risk [38]. While these new developments hold great promise, they have so far been studied in few patients only.

At present, there are only limited data with regard to the natural evolution of postinfarction edema by CMR. In a canine model, edema could be detected by CMR shortly after coronary occlusion [39]. In a small study of patients with STEMI, edema was not significantly different between day 1 and 1 week after infarction [40]. It is unclear how long edema persists following myocardial infarction. In patients with hypertrophic obstructive cardiomyopathy undergoing septal artery embolization, edema could be found after 28 days in all patients, whereas it was no longer present after 3 months [41]. Other studies in acute reperfused ST-elevation myocardial infarction patients have shown long-lasting postinfarction edema up to 12 months $[42,43]$.

Image Analysis Most of the techniques described for the measurement of infarct size also apply to edema assessment. However, due to the aforementioned limitations of current $\mathrm{T} 2$ sequences for edema assessment, image analysis can be challenging in some patients. Image interpretation depends on regional differences in myocardial signal intensity and the purely visual delineation of edema borders offers the potential for subjective error. Cut-off values for defining abnormal vs. normal tissue for semiautomated quantification are not sufficiently standardized. A quantitative T2 mapping technique has recently been introduced which offers the potential for increased accuracy in image analysis [38].

Validity and reliability SPECT myocardial salvage has been successfully used as a surrogate endpoint in several clinical trials [44-46] and the first studies using myocardial salvage by CMR as a primary endpoint have been published $[47,48]$. Recently, a study showed that the amount of myocardial salvage assessed by CMR also predicts patient outcome [49]. The prognostic value of the salvage area at risk is consistent with previous SPECT studies [50]. However, as with infarct size, there are yet no clear data demonstrating that specific therapies able to increase myocardial salvage can also favorably influence patient-relevant endpoints. Recently, acceptable reliability for myocardial salvage assessment has been shown [51].

Comparison to alternative methods Myocardial salvage can also be assessed by SPECT $[44,46]$. However, CMR has several advantages over SPECT. As mentioned above, CMR yields higher spatial resolution which 
allows the assessment of small subendocardial infarcts often elusive to SPECT imaging [6,27]. Furthermore, CMR can assess the salvaged myocardium retrospectively a few days after infarction and does therefore not interfere with acute patient management (in SPECT imaging the radioactive tracer must be injected before recanalization of the infarct-related artery in the emergency department setting). Salvage assessment by CMR can also be performed with a single examination whereas in SPECT it is necessary to perform two subsequent measurements for assessment of the initial perfusion defect and final infarct size. Finally, CMR avoids radiation exposure. CMR may therefore be superior to assess myocardial salvage.

Microvascular Obstruction

Basic Description Early recanalization of the infarctrelated artery is the primary treatment target in the first hours after symptom onset in acute STEMI [52]. However, restoration of epicardial flow does not necessarily translate into adequate perfusion of the microcirculation. Areas of impaired microcirculatory flow can be directly visualised and quantified by CMR as microvascular obstruction. Following contrast administration infarcted zones take up gadolinium and subsequently appear bright. However, in areas of severely compromized perfusion contrast take-up is absent. Areas of microvascular obstruction can therefore be visualised as dark areas within the bright infarct (Figure 3).

Several methods for the assessment of microvascular obstruction by CMR have been proposed [53]. Image acquisition during first myocardial pass of gadolinium,

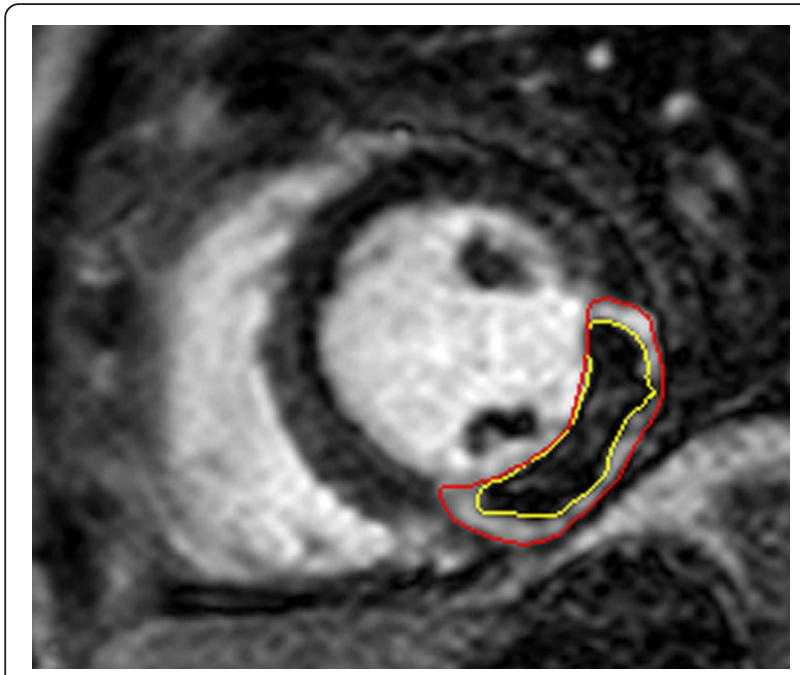

Figure 3 Late enhancement CMR imaging showing infarcted myocardium (red contours) in a patient with lateral STEMI due to occluded left circumflex artery. The central hypointense core within the infarct represents microvascular obstruction (yellow contours). early imaging in the first minutes after contrast administration and late imaging approximately 15 minutes after contrast injection. The extent of microvascular obstruction gradually declines between first-pass and late imaging. The observed differences over time reflect the persistent slow diffusion of contrast or collateral filling into areas with a less compromized microcirculation. These regions subsequently display smaller or completely absent zones of hypoenhancement on late imaging. Microvascular obstruction on late imaging therefore likely reflects areas of a more severely disturbed microcirculation whereas microvascular obstruction on early imaging is more sensitive for the detection of only small or less impaired areas of microvascular injury. At present, there is no consensus which of these slightly differing techniques to apply. However, in the largest patient series to date late image acquisition (approximately 15 minutes after contrast administration) was superior to early image acquisition (approximately 1 minute post contrast administration) in predicting clinical outcome [54]. Myocardial regions displaying delayed, yet not fully absent perfusion might therefore be of only minor importance for clinical prognosis.

Given the time dependency of presence and extent of microvascular obstruction on the time between contrast administration and image acquisition, it is important to adhere to strict methodology within the clinical trial setting.

Image Analysis Quantitative analysis of microvascular obstruction within the infarct zone is performed in a stack of short-axis slices using either manual planimetry or semiautomatic methods. Techniques are similar to those described above for the assessment of infarct size.

Validity and reliability Microvascular obstruction is reasonably valid to be used as a surrogate endpoint in clinical trials. Numerous studies relating to pathophysiological mechanisms have been published [55] and the association of CMR microcirculatory injury and adverse clinical prognosis is well established [54,56,57]. However, as with infarct size and myocardial salvage, proof is lacking that therapeutic measures able to reduce markers of microvascular obstruction can also favorably influence true clinical endpoints [55]. There are yet no published reliability studies for the assessment of microvascular obstruction.

Comparison to alternative methods Several other modalities are available for detecting microvascular obstruction such as myocardial blush grading on invasive angiography, evaluation of electrocardiographic ST-resolution or myocardial contrast echocardiography. Microvascular obstruction assessed by CMR might be superior to myocardial blush grading and ST-resolution in predicting functional recovery after myocardial infarction $[58,59]$. In contrast to myocardial blush grading, CMR 
image acquisition for the assessment of microvascular obstruction is not performed immediately following coronary intervention. This might be advantageous since microvascular obstruction often expands during the first hours following reperfusion. Therefore, very early measurement might not reflect the true quantitative extent [60].

\section{Left ventricular ejection fraction and volumes}

Basic Description CMR measures ventricular volumes and mass using a simple acquisition of a 3-dimensional stack of contiguous short-axis cines with full biventricular coverage. Currently, the standard technique to measure left ventricular ejection fraction and volumes is a breathhold, SSFP sequence that provides optimal contrast between blood and myocardium. Current cine sequences use retrospective electrocardiographic gating, although prospective gating may be required in patients with irregular heart rhythm. A portion of the data is recorded during each cardiac cycle and data from several heart beats are then fused to form a continuous cine movie loop.

Image Analysis Calculation of left ventricular ejection fraction and volumes is commonly performed in short axis images following planimetry of endocardial and epicardial contours. The borders are typically traced at enddiastole and endsystole.

Validity and reliability Left ventricular ejection fraction and volumes are important predictors for survival after acute myocardial infarction $[61,62]$. CMR is an accurate and highly reproducible technique for measuring left ventricular ejection fraction and volumes and is thus well suited to assess postinfarction remodelling through serial assessment of left ventricular function and morphology [63].

Comparison to alternative methods Echocardiography and gated SPECT are widely available techniques available for measuring cardiac function and volumes. Gated SPECT suffers from relatively low spatial resolution. Compared to echocardiography, CMR has been shown to be significantly more accurate with less interobserver and intraobserver variability as well as superior reproducibility [64]. Notably, CMR assessment of the aforementioned parameters is less dependent on geometric assumptions. This aspect is especially important in patients after myocardial infarction where regional alterations of left ventricular geometry are frequent (e.g. aneurysms). Consequently, CMR is the technique of choice for longitudinal studies of left ventricular ejection fraction or remodelling over time.

\section{Other CMR parameters}

Intramyocardial Hemorrhage A subset of patients with acute myocardial infarction display hypointense zones within the area at risk in T2-weighted spin echo sequences (Figure 4) [65]. These regions likely correspond to intramyocardial hemorrhage and are associated

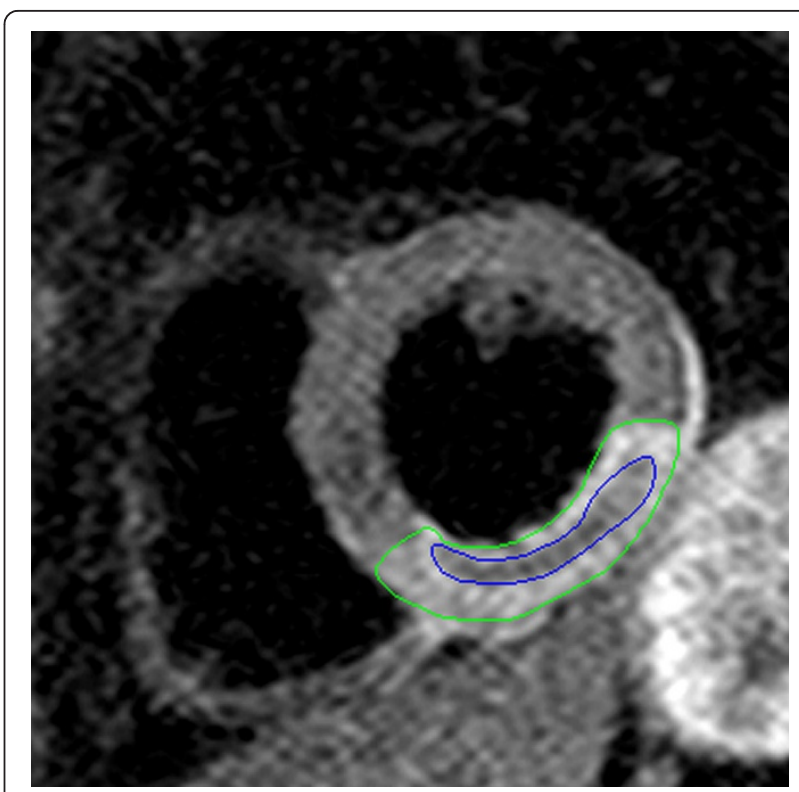

Figure 4 T2-weighted spin echo imaging in a patient with inferior/inferolateral STEMI due to occluded right coronary artery showing myocardial edema (green contours). The

hypointense zones within the edematous region likely represent intramyocardial hemorrhage (blue contours).

with adverse remodelling of the left ventricle [65]. T2*weighted gradient echo sequences are also able to visualise hemorrhagic infarcts and might be more sensitive to the susceptibility effects of hemorrhage than spin-echo imaging [66]. The presence of such hemorrhage is associated with microvascular obstruction and has been shown to be a strong predictor of adverse remodelling after infarction $[65,67]$. However, the clinical significance of intramyocardial hemorrhage on hard clinical outcome has not yet been established. In conclusion, further validation and reliability studies are necessary for this parameter to qualify as a surrogate endpoint in clinical trials. Infarct core and border zone The infarct region can be further subclassified into core and border zone depending on relative signal intensity as compared to normal myocardium (semiautomatic analysis). In one trial the infarct core has been defined by a signal intensity $\geq 3$ standard deviations of remote normal myocardium whereas the periinfarct border zone was classified by a signal intensity between 2 and 3 standard deviations [68]. The border zone represents a mixture of healthy and structurally damaged myocytes and might be a substrate of ventricular arrhythmia [69]. The topic has so far been studied in only few patients in the chronic phase after infarction.

\section{General limitations of post-infarct CMR imaging}

Important limitations of CMR imaging in post-infarct patients are contraindications such as pacemakers, internal defibrillators, claustrophobia or hemodynamic and 
electrical instability. Also, there are concerns about the use of gadolinium based contrast agents in patients with advanced renal failure due to the risk of developing nephrogenic systemic fibrosis [70]. When planning a trial in myocardial infarction with CMR endpoints, one should be aware that these factors are often defined as exclusion criteria. Even in the cohort finally randomized, $5-10 \%$ of patients will eventually not undergo CMR examination for various reasons $[25,48]$. Furthermore, in patients with atrial fibrillation or significant ventricular ectopy, there can be degradation in image quality.

\section{Randomized controlled STEMI trials with primary CMR endpoints}

Table 1 summarizes published randomized controlled trials for the treatment of myocardial infarction in the acute setting using CMR parameters as a primary study endpoint (restricted to trials published until December 2010 and listed in MEDLINE). Trials with a non-CMR primary endpoint or those not defining the primary endpoint were excluded. Numerous further studies are currently being conducted.

\section{Summary and conclusions}

CMR is a safe technique, even in the first days after infarction and offers a variety of established and novel parameters potentially suitable as surrogate endpoints in clinical trials of STEMI. It allows the evaluation of function, infarct extent, salvaged myocardium and microvascular obstruction, and can be acquired easily within 30 to 40 minutes. The choice of marker is naturally dependent on the specific question of the trial to be conducted.

Table 1 Randomized controlled trials for the treatment of myocardial infarction in the acute setting using CMR parameters as a primary study endpoint (sorted by date of publication)

\begin{tabular}{|c|c|c|c|c|}
\hline Primary CMR endpoint & Study & Treatment & $\begin{array}{l}\text { Number of } \\
\text { patients }\end{array}$ & $\begin{array}{l}\text { Year } \\
\text { published }\end{array}$ \\
\hline Myocardial salvage index at days $2-4$ & $\begin{array}{l}\text { Thiele et al. (LIPSIA-N-ACC } \\
\text { study)[48] }\end{array}$ & High-dose N-acetylcysteine & 251 & 2010 \\
\hline $\begin{array}{l}\text { LV endsystolic volume index at 10-14 } \\
\text { weeks }\end{array}$ & Abbate et al.[71] & Interleukin-1 blockade with anakinra & 10 & 2010 \\
\hline LV ejection fraction at 6 months & Wöhrle et al.[72] & $\begin{array}{l}\text { Autologous intracoronary bone-marrow cell } \\
\text { therapy }\end{array}$ & 42 & 2010 \\
\hline Myocardial salvage at 3 months & Lonborg et al.[47] & Ischemic postconditioning & 118 & 2010 \\
\hline Infarct size at 4-6 months & Haeck et al.[73] & $\begin{array}{l}\text { Proximal embolic protection and thrombus } \\
\text { aspiration }\end{array}$ & 206 & 2010 \\
\hline $\begin{array}{l}\text { Infarct size and LV ejection fraction at } \\
90 \text { days }\end{array}$ & $\begin{array}{l}\text { Patel et al. (APEX-AMI trial) } \\
\text { [74] }\end{array}$ & Pexelizumab (anti-C5 complement antibody) & 99 & 2010 \\
\hline $\begin{array}{l}\text { LV endsystolic volume index at } 24 \\
\text { weeks }\end{array}$ & Weir et al.[75] & Eplerenone & 100 & 2009 \\
\hline LV ejection fraction at 6 months & $\begin{array}{l}\text { Tendera et al. (REGENT study) } \\
\text { [76] }\end{array}$ & $\begin{array}{l}\text { Intracoronary infusion of bone-marrow } \\
\text { derived selected CD34+CXCR4+ cells versus } \\
\text { non-selected mononuclear cells }\end{array}$ & 200 & 2009 \\
\hline Infarct size at 1 month & Song et al.[77] & Upstream high-dose tirofiban treatment & & 2009 \\
\hline LV ejection fraction at 4 and 12 months & Dill et al.[78] & $\begin{array}{l}\text { Intracoronary administration of bone- } \\
\text { marrow derived progenitor cells }\end{array}$ & 54 & 2009 \\
\hline Infarct size after 5 days & Atar et al. (FIRE study)[79] & FX06 & 234 & 2009 \\
\hline $\begin{array}{l}\text { Infarct size and microvascular } \\
\text { obstruction at } 2 \text { days }\end{array}$ & Thiele et al.[25] & $\begin{array}{l}\text { Intracoronary versus intravenous bolus } \\
\text { abciximab application }\end{array}$ & 144 & 2008 \\
\hline Infarct size at 3 days & Hahn et al.[80] & Distal protection device & 39 & 2007 \\
\hline $\begin{array}{l}\text { Global and regional myocardial function } \\
\text { at } 3 \text { months }\end{array}$ & Engelmann et al.[81] & Granulocyte colony-stimulating factor & 44 & 2006 \\
\hline LV ejection fraction at 6 months & $\begin{array}{l}\text { Kang et al. (MAGIC Cell-3-DES } \\
\text { trial)[82] }\end{array}$ & $\begin{array}{l}\text { Intracoronary infusion of mobilized } \\
\text { peripheral blood stem cells }\end{array}$ & 96 & 2006 \\
\hline Systolic wall thickening at 6 months & Ripa et al. (STEMMI trial)[83] & Granulocyte colony-stimulating factor & 78 & 2006 \\
\hline LV ejection fraction at 4 months & Janssens[84] & $\begin{array}{l}\text { Transfer of autologous bone-marrow } \\
\text { derived stem cells in the infarct-related } \\
\text { artery }\end{array}$ & 67 & 2006 \\
\hline Infarct size at 6 months & Thiele et al.[85] & $\begin{array}{l}\text { Pre-hospital combination-fibrinolysis plus } \\
\text { conventional care versus pre-hospital } \\
\text { combination-fibrinolysis plus facilitated } \\
\text { percutaneous coronary intervention }\end{array}$ & 164 & 2005 \\
\hline LV ejection fraction at 6 months & Wollert et al. (BOOST trial)[86] & $\begin{array}{l}\text { Intracoronary transfer of autologous bone- } \\
\text { marrow cells }\end{array}$ & 60 & 2004 \\
\hline LV volumes at 6 months & Darasz et al.[87] & Captopril and xamoterol & 70 & 1995 \\
\hline
\end{tabular}


However, choosing the most appropriate surrogate endpoint for the question at hand cannot restrict itself to a biologically plausible association between surrogate and clinical outcome. Other qualities of validity must also be demonstrated. Furthermore, surrogate endpoints should demonstrate high measurement reliability which can be considered a specific strength of most CMR parameters. Definite proof of validity is more difficult to establish. Therefore, the use of CMR surrogate endpoints in trials of myocardial infarction mandates a thoughtful interpretation of study results. It seems reasonable to use CMR surrogate endpoint studies mainly to prove fundamental biological activity and to evaluate pathophysiological mechanisms of novel therapeutic interventions. This can ultimately guide the decision whether to conduct larger studies with endpoints truly relevant to patients. Further studies should focus to address some of the limitations of CMR endpoints in myocardial infarction.

\section{List of abbreviations}

STEMI: ST-elevation myocardial infarction; CMR: Cardiac magnetic resonance; ICH: International Conference on Harmonisation; SPECT: Single photon emission computed tomography; TSE: Turbo spin echo; SSFP: steady state free precession.

\section{Acknowledgements \\ None.}

Source of funding

All authors are employees of the the University of Leipzig - Heart Center, Germany, which funded the work. The funding institution had no role in writing of the manuscript and in the decision to submit the manuscript for publication.

\section{Author details}

'University of Leipzig - Heart Center, Department of Internal Medicine/ Cardiology, Leipzig, Germany. ${ }^{2}$ University of Leipzig - Heart Center, Department of Diagnostic and Interventional Radiology, Leipzig, Germany.

\section{Authors' contributions}

SD drafted the initial version of the manuscript. All authors made substantial contributions in critically revising the manuscript for important intellectual content, read and approved the final version.

\section{Competing interests}

The authors declare that they have no competing interests.

Received: 26 April 2011 Accepted: 14 September 2011 Published: 14 September 2011

\section{References}

1. Burzykowski T, Molenberghs G, Buyse M, editors: The Evaluation of Surrogate Endpoints. New York: Springer; 2005.

2. Nimmo W, Tucker G, editors: A regulatory authority's opinion about surrogate endpoints. Clinical Measurement in Drug Evaluation New York: John Wiley \& Sons; 1995.

3. Biomarkers and surrogate endpoints: preferred definitions and conceptual framework. Clin Pharmacol Ther 2001, 69:89-95.

4. Committee for Proprietary Medicinal Products (CPMP). Statistical Prinicples for Clinical Trials (ICH Topic E9). CPMP/ICH/363/96. Book Committee for Proprietary Medicinal Products (CPMP). Statistical Prinicples for Clinical Trials (ICH Topic E9). CPMP/ICH/363/96 European Medicines Agency City; 1998.

5. Kim RJ, Fieno DS, Parrish TB, Harris K, Chen EL, Simonetti O, Bundy J, Finn JP, Klocke FJ, Judd RM: Relationship of MRI delayed contrast enhancement to irreversible injury, infarct age, and contractile function. Circulation 1999, 100:1992-2002.

6. Wagner A, Mahrholdt H, Holly TA, Elliott MD, Regenfus M, Parker M, Klocke FJ, Bonow RO, Kim RJ, Judd RM: Contrast-enhanced MRI and routine single photon emission computed tomography (SPECT) perfusion imaging for detection of subendocardial myocardial infarcts: an imaging study. Lancet 2003, 361:374-379.

7. Engblom H, Hedstrom E, Heiberg E, Wagner GS, Pahlm O, Arheden H: Rapid initial reduction of hyperenhanced myocardium after reperfused first myocardial infarction suggests recovery of the peri-infarction zone: one-year follow-up by MRI. Circ Cardiovasc Imaging 2009, 2:47-55.

8. Ibrahim T, Hackl T, Nekolla SG, Breuer M, Feldmair M, Schomig A, Schwaiger M: Acute myocardial infarction: serial cardiac MR imaging shows a decrease in delayed enhancement of the myocardium during the 1st week after reperfusion. Radiology 2010, 254:88-97.

9. Kramer CM, Barkhausen J, Flamm SD, Kim RJ, Nagel E: Standardized cardiovascular magnetic resonance imaging (CMR) protocols, society for cardiovascular magnetic resonance: board of trustees task force on standardized protocols. J Cardiovasc Magn Reson 2008, 10:35.

10. Kellman $P$, Arai $A E$, McVeigh ER, Aletras AH: Phase-sensitive inversion recovery for detecting myocardial infarction using gadolinium-delayed hyperenhancement. Magn Reson Med 2002, 47:372-383.

11. Geiser EA, Bove KE: Calculation of left ventricular mass and relative wall thickness. Arch Pathol 1974, 97:13-21.

12. Bondarenko O, Beek AM, Hofman MB, Kühl HP, Twisk JW, van Dockum WG, Visser CA, van Rossum AC: Standardizing the definition of hyperenhancement in the quantitative assessment of infarct size and myocardial viability using delayed contrast-enhanced CMR. J Cardiovasc Magn Reson 2005, 7:481-485.

13. Kim HW, Klem I, Shah DJ, Wu E, Meyers SN, Parker MA, Crowley AL, Bonow RO, Judd RM, Kim RJ: Unrecognized non-Q-wave myocardial infarction: prevalence and prognostic significance in patients with suspected coronary disease. PLoS Med 2009, 6:e1000057.

14. Thiele H, Kappl MJ, Conradi S, Niebauer J, Hambrecht R, Schuler G: Reproducibility of chronic and acute infarct size measurement by delayed enhancement magnetic resonance imaging. J Am Coll Cardiol 2006, 47:1641-1645.

15. Kim HW, Farzaneh-Far A, Kim RJ: Cardiovascular magnetic resonance in patients with myocardial infarction: current and emerging applications. $J$ Am Coll Cardiol 2009, 55:1-16.

16. Fieno DS, Kim RJ, Chen EL, Lomasney JW, Klocke FJ, Judd RM: Contrastenhanced magnetic resonance imaging of myocardium at risk: distinction between reversible and irreversible injury throughout infarct healing. J Am Coll Cardiol 2000, 36:1985-1991.

17. Amado LC, Gerber BL, Gupta SN, Rettmann DW, Szarf G, Schock R, Nasir K, Kraitchman DL, Lima JA: Accurate and objective infarct sizing by contrastenhanced magnetic resonance imaging in a canine myocardial infarction model. J Am Coll Cardiol 2004, 44:2383-2389.

18. Flett AS, Hasleton J, Cook C, Hausenloy D, Quarta G, Ariti C, Muthurangu V, Moon JC: Evaluation of techniques for the quantification of myocardial scar of differing etiology using cardiac magnetic resonance. JACC Cardiovasc Imaging 2011, 4:150-156.

19. Heiberg E, Ugander M, Engblom H, Gotberg M, Olivecrona GK, Erlinge D, Arheden $\mathrm{H}$ : Automated quantification of myocardial infarction from MR images by accounting for partial volume effects: animal, phantom, and human study. Radiology 2008, 246:581-588.

20. Hsu LY, Ingkanisorn WP, Kellman P, Aletras AH, Arai AE: Quantitative myocardial infarction on delayed enhancement MRI. Part II: Clinical application of an automated feature analysis and combined thresholding infarct sizing algorithm. J Magn Reson Imaging 2006, 23:309-314.

21. Hsu LY, Natanzon A, Kellman P, Hirsch GA, Aletras AH, Arai AE: Quantitative myocardial infarction on delayed enhancement MRI. Part I: Animal validation of an automated feature analysis and combined thresholding infarct sizing algorithm. J Magn Reson Imaging 2006, 23:298-308.

22. Choi KM, Kim RJ, Gubernikoff G, Vargas JD, Parker M, Judd RM: Transmural extent of acute myocardial infarction predicts long-term improvement in contractile function. Circulation 2001, 104:1101-1107.

23. Larose E, Rodes-Cabau J, Pibarot P, Rinfret S, Proulx G, Nguyen CM, Dery JP, Gleeton O, Roy L, Noel B, et al: Predicting late myocardial recovery and outcomes in the early hours of ST-segment elevation myocardial 
infarction traditional measures compared with microvascular obstruction, salvaged myocardium, and necrosis characteristics by cardiovascular magnetic resonance. J Am Coll Cardiol 2010, 55:2459-2469.

24. Wu E, Ortiz JT, Tejedor P, Lee DC, Bucciarelli-Ducci C, Kansal P, Carr JC, Holly TA, Lloyd-Jones D, Klocke FJ, Bonow RO: Infarct size by contrast enhanced cardiac magnetic resonance is a stronger predictor of outcomes than left ventricular ejection fraction or end-systolic volume index: prospective cohort study. Heart 2008, 94:730-736.

25. Thiele H, Schindler K, Friedenberger J, Eitel I, Furnau G, Grebe E, Erbs S, Linke A, Mobius-Winkler S, Kivelitz D, Schuler G: Intracoronary compared with intravenous bolus abciximab application in patients with STelevation myocardial infarction undergoing primary percutaneous coronary intervention: the randomized Leipzig immediate percutaneous coronary intervention abciximab IV versus IC in ST-elevation myocardial infarction trial. Circulation 2008, 118:49-57.

26. Thiele H, Wohrle J, Neuhaus P, Brosteanu O, Sick P, Prondzinsky R, Birkemeyer R, Wiemer M, Kerber S, Schuehlen $\mathrm{H}$, et al: Intracoronary compared with intravenous bolus abciximab application during primary percutaneous coronary intervention: design and rationale of the Abciximab Intracoronary versus intravenously Drug Application in STElevation Myocardial Infarction (AIDA STEMI) trial. Am Heart J 2010, 159:547-554.

27. Ibrahim T, Bulow HP, Hackl T, Hornke M, Nekolla SG, Breuer M, Schomig A, Schwaiger M: Diagnostic value of contrast-enhanced magnetic resonance imaging and single-photon emission computed tomography for detection of myocardial necrosis early after acute myocardial infarction. J Am Coll Cardiol 2007, 49:208-216.

28. Miller TD, Christian TF, Hopfenspirger MR, Hodge DO, Gersh BJ, Gibbons RJ: Infarct size after acute myocardial infarction measured by quantitative tomographic $99 \mathrm{mTc}$ sestamibi imaging predicts subsequent mortality. Circulation 1995, 92:334-341.

29. Ibrahim T, Nekolla SG, Hornke M, Bulow HP, Dirschinger J, Schomig A, Schwaiger M: Quantitative measurement of infarct size by contrastenhanced magnetic resonance imaging early after acute myocardial infarction: comparison with single-photon emission tomography using Tc99m-sestamibi. J Am Coll Cardiol 2005, 45:544-552.

30. Gibbons RJ, Valeti US, Araoz PA, Jaffe AS: The quantification of infarct size. J Am Coll Cardiol 2004, 44:1533-1542.

31. Aletras AH, Tilak GS, Natanzon A, Hsu L-Y, Gonzalez FM, Hoyt RF Jr, Arai AE: Retrospective determination of the area at risk for reperfused acute myocardial infarction with T2-weighted cardiac magnetic resonance imaging: Histopathological and displacement encoding with stimulated echoes (DENSE) functional validations. Circulation 2006, 113:1865-1870.

32. Friedrich MG, Abdel-Aty H, Taylor A, Schulz-Menger J, Messroghli D, Dietz R: The salvaged area at risk in reperfused acute myocardial infarction as visualized by cardiovascular magnetic resonance. J Am Coll Cardiol 2008, 51:1581-1587.

33. Reimer KA, Jennings RB, Cobb FR, Murdock RH, Greenfield JCJ, Becker LC, Bulkley BH, Hutchins GM, Schwartz RPJ, Bailey KR: Animal models for protecting ischemic myocardium: results of the NHLBI Cooperative Study: comparison of unconscious and conscious dog models. Circ Res 1985, 56:651-665.

34. Lowe JE, Reimer KA, Jennings RB: Experimental infarct size as a function of the amount of myocardium at risk. Am J Pathol 1978, 90:363-379.

35. Abdel-Aty H, Simonetti O, Friedrich MG: T2-weighted cardiovascular magnetic resonance imaging. J Magn Reson Imaging 2007, 26:452-459.

36. Kellman P, Aletras AH, Mancini C, McVeigh ER, Arai AE: T2-prepared SSFP improves diagnostic confidence in edema imaging in acute myocardial infarction compared to turbo spin echo. Magn Reson Med 2007, 57:891-897.

37. Aletras AH, Kellman P, Derbyshire JA, Arai AE: ACUT2E TSE-SSFP: a hybrid method for T2-weighted imaging of edema in the heart. Magn Reson Med 2008, 59:229-235.

38. Giri S, Chung YC, Merchant A, Mihai G, Rajagopalan S, Raman SV, Simonetti OP: T2 quantification for improved detection of myocardial edema. J Cardiovasc Magn Reson 2009, 11:56.

39. Abdel-Aty H, Cocker M, Meek C, Tyberg JV, Friedrich MG: Edema as a very early marker for acute myocardial ischemia: a cardiovascular magnetic resonance study. J Am Coll Cardiol 2009, 53:1194-1201.

40. Carlsson M, Ubachs JF, Hedstrom E, Heiberg E, Jovinge S, Arheden H: Myocardium at risk after acute infarction in humans on cardiac magnetic resonance: quantitative assessment during follow-up and validation with single-photon emission computed tomography. JACC Cardiovasc Imaging 2009, 2:569-576.

41. Schulz-Menger J, Gross M, Messroghli D, Uhlich F, Dietz R, Friedrich MG: Cardiovascular magnetic resonance of acute myocardial infarction at a very early stage. J Am Coll Cardiol 2003, 42:513-518.

42. Nilsson JC, Nielsen G, Groenning BA, Fritz-Hansen T, Sondergaard L, Jensen GB, Larsson HB: Sustained postinfarction myocardial oedema in humans visualised by magnetic resonance imaging. Heart 2001, 85:639-642.

43. Ripa RS, Nilsson JC, Wang Y, Sondergaard L, Jorgensen E, Kastrup J: Shortand long-term changes in myocardial function, morphology, edema, and infarct mass after ST-segment elevation myocardial infarction evaluated by serial magnetic resonance imaging. Am Heart J 2007, 154:929-936

44. Kastrati A, Mehilli J, Dirschinger J, Schricke U, Neverve J, Pache J, Martinoff S, Neumann FJ, Nekolla S, Blasini R, et al: Myocardial salvage after coronary stenting plus abciximab versus fibrinolysis plus abciximab in patients with acute myocardial infarction: a randomised trial. Lancet 2002, 359:920-925

45. Milavetz JJ, Giebel DW, Christian TF, Schwartz RS, Holmes DR Jr, Gibbons RJ: Time to therapy and salvage in myocardial infarction. J Am Coll Cardiol 1998, 31:1246-1251.

46. Schomig A, Kastrati A, Dirschinger J, Mehilli J, Schricke U, Pache J, Martinoff S, Neumann FJ, Schwaiger M: Coronary stenting plus platelet glycoprotein Ilb/lla blockade compared with tissue plasminogen activator in acute myocardial infarction. Stent versus Thrombolysis for Occluded Coronary Arteries in Patients with Acute Myocardial Infarction Study Investigators. N Engl J Med 2000, 343:385-391.

47. Lonborg J, Kelbaek H, Vejlstrup N, Jorgensen E, Helqvist S, Saunamaki K, Clemmensen P, Holmvang L, Treiman M, Jensen JS, Engstrom T: Cardioprotective effects of ischemic postconditioning in patients treated with primary percutaneous coronary intervention, evaluated by magnetic resonance. Circ Cardiovasc Interv 2010, 3:34-41.

48. Thiele H, Hildebrand L, Schirdewahn C, Eitel I, Adams V, Fuernau G, Erbs S, Linke A, Diederich KW, Nowak M, et al: Impact of high-dose Nacetylcysteine versus placebo on contrast-induced nephropathy and myocardial reperfusion injury in unselected patients with ST-segment elevation myocardial infarction undergoing primary percutaneous coronary intervention. The LIPSIA-N-ACC (Prospective, Single-Blind, Placebo-Controlled, Randomized Leipzig Immediate PercutaneouS Coronary Intervention Acute Myocardial Infarction N-ACC) Trial. J Am Coll Cardiol 2010, 55:2201-2209.

49. Eitel I, Desch S, Fuernau G, Hildebrand L, Gutberlet M, Schuler G, Thiele H: Prognostic significance and determinants of myocardial salvage assessed by cardiovascular magnetic resonance in acute reperfused myocardial infarction. J Am Coll Cardiol 2010, 55:2470-2479.

50. Ndrepepa G, Mehilli J, Schwaiger M, Schuhlen H, Nekolla S, Martinoff S, Schmitt C, Dirschinger J, Schomig A, Kastrati A: Prognostic value of myocardial salvage achieved by reperfusion therapy in patients with acute myocardial infarction. J Nucl Med 2004, 45:725-729.

51. Desch S, Engelhardt H, Meissner J, Eitel I, Sareban M, Fuernau G, de Waha S, Grothoff M, Gutberlet M, Schuler G, Thiele H: Reliability of myocardial salvage assessment by cardiac magnetic resonance imaging in acute reperfused myocardial infarction. Int J Cardiovasc Imaging 2011.

52. Van de Werf F, Bax J, Betriu A, Blomstrom-Lundqvist C, Crea F, Falk V, Filippatos G, Fox K, Huber K, Kastrati A, et al: Management of acute myocardial infarction in patients presenting with persistent ST-segment elevation: The Task Force on the management of ST-segment elevation acute myocardial infarction of the European Society of Cardiology. Eur Heart J 2008, 29:2909-2945.

53. Mather AN, Lockie T, Nagel E, Marber M, Perera D, Redwood S, Radjenovic A, Saha A, Greenwood JP, Plein S: Appearance of microvascular obstruction on high resolution first-pass perfusion, early and late gadolinium enhancement CMR in patients with acute myocardial infarction. J Cardiovasc Magn Reson 2009, 11:33.

54. de Waha S, Desch S, Eitel I, Fuernau G, Zachrau J, Leuschner A, Gutberlet M, Schuler $\mathrm{G}$, Thiele $\mathrm{H}$ : Impact of early vs. late microvascular obstruction assessed by magnetic resonance imaging on long-term outcome after ST-elevation myocardial infarction: a comparison with traditional prognostic markers. Eur Heart J 2010, 31:2660-2668. 
55. Bekkers SC, Yazdani SK, Virmani R, Waltenberger J: Microvascular obstruction: underlying pathophysiology and clinical diagnosis. J Am Coll Cardiol 2010, 55:1649-1660

56. Hombach V, Grebe O, Merkle N, Waldenmaier S, Hoher M, Kochs M, Wohrle J, Kestler HA: Sequelae of acute myocardial infarction regarding cardiac structure and function and their prognostic significance as assessed by magnetic resonance imaging. Eur Heart J 2005, 26:549-557.

57. Wu KC, Zerhouni EA, Judd RM, Lugo-Olivieri CH, Barouch LA, Schulman SP, Blumenthal RS, Lima JA: Prognostic significance of microvascular obstruction by magnetic resonance imaging in patients with acute myocardial infarction. Circulation 1998, 97:765-772.

58. Nijveldt R, Beek AM, Hirsch A, Stoel MG, Hofman MB, Umans VA, Algra PR, Twisk JW, van Rossum AC: Functional recovery after acute myocardial infarction: comparison between angiography, electrocardiography, and cardiovascular magnetic resonance measures of microvascular injury. $J$ Am Coll Cardiol 2008, 52:181-189.

59. Vicente J, Mewton N, Croisille P, Staat P, Bonnefoy-Cudraz E, Ovize M, Revel D: Comparison of the angiographic myocardial blush grade with delayed-enhanced cardiac magnetic resonance for the assessment of microvascular obstruction in acute myocardial infarctions. Catheter Cardiovasc Interv 2009, 74:1000-1007.

60. Ambrosio G, Weisman HF, Mannisi JA, Becker LC: Progressive impairment of regional myocardial perfusion after initial restoration of postischemic blood flow. Circulation 1989, 80:1846-1861.

61. Risk stratification and survival after myocardial infarction. N Engl J Med 1983, 309:331-336.

62. White HD, Norris RM, Brown MA, Brandt PW, Whitlock RM, Wild CJ: Left ventricular end-systolic volume as the major determinant of survival after recovery from myocardial infarction. Circulation 1987, 76:44-51.

63. Pennell DJ: Cardiovascular magnetic resonance. Circulation 2010, 121:692-705

64. Bellenger NG, Grothues F, Smith GC, Pennell DJ: Quantification of right and left ventricular function by cardiovascular magnetic resonance. Herz 2000, 25:392-399.

65. Ganame J, Messalli G, Dymarkowski S, Rademakers FE, Desmet W, Van de Werf F, Bogaert J: Impact of myocardial haemorrhage on left ventricular function and remodelling in patients with reperfused acute myocardial infarction. Eur Heart J 2009, 30:1440-1449.

66. O'Regan DP, Ahmed R, Karunanithy N, Neuwirth C, Tan Y, Durighel G, Hajnal JV, Nadra I, Corbett SJ, Cook SA: Reperfusion hemorrhage following acute myocardial infarction: assessment with $\mathrm{T} 2 *$ mapping and effect on measuring the area at risk. Radiology 2009, 250:916-922.

67. O'Regan DP, Ariff B, Neuwirth C, Tan Y, Durighel G, Cook SA: Assessment of severe reperfusion injury with $\mathrm{T}^{*}$ cardiac MRI in patients with acute myocardial infarction. Heart 96:1885-1891.

68. Yan AT, Shayne AJ, Brown KA, Gupta SN, Chan CW, Luu TM, Di Carli MF, Reynolds HG, Stevenson WG, Kwong RY: Characterization of the periinfarct zone by contrast-enhanced cardiac magnetic resonance imaging is a powerful predictor of post-myocardial infarction mortality. Circulation 2006, 114:32-39.

69. Schmidt A, Azevedo CF, Cheng A, Gupta SN, Bluemke DA, Foo TK, Gerstenblith G, Weiss RG, Marban E, Tomaselli GF, et al: Infarct tissue heterogeneity by magnetic resonance imaging identifies enhanced cardiac arrhythmia susceptibility in patients with left ventricular dysfunction. Circulation 2007, 115:2006-2014.

70. Kribben A, Witzke O, Hillen U, Barkhausen J, Daul AE, Erbel R: Nephrogenic systemic fibrosis: pathogenesis, diagnosis, and therapy. J Am Coll Cardiol 2009, 53:1621-1628.

71. Abbate A, Kontos MC, Grizzard JD, Biondi-Zoccai GG, Van Tassell BW, Robati R, Roach LM, Arena RA, Roberts CS, Varma A, et al: Interleukin-1 blockade with anakinra to prevent adverse cardiac remodeling after acute myocardial infarction (Virginia Commonwealth University Anakinra Remodeling Trial [VCU-ART] Pilot study). Am J Cardiol 2010, 105:1371-1377, e1371.

72. Wohrle J, Merkle N, Mailander V, Nusser T, Schauwecker P, von Scheidt F, Schwarz K, Bommer M, Wiesneth M, Schrezenmeier H, Hombach V: Results of intracoronary stem cell therapy after acute myocardial infarction. Am J Cardiol 2010, 105:804-812

73. Haeck JD, Kuijt WJ, Koch KT, Bilodeau L, Henriques JP, Rohling WJ, Baan J Jr, Vis MM, Nijveldt R, van Geloven N, et al: Infarct size and left ventricular function in the PRoximal Embolic Protection in Acute myocardial infarction and Resolution of ST-segment Elevation (PREPARE) trial: ancillary cardiovascular magnetic resonance study. Heart 2010, 96:190-195.

74. Patel MR, Worthley SG, Stebbins A, Dill T, Rademakers FE, Velleti US, Barsness GW, Van de Werf F, Hamm CW, Armstrong PW, et al: Pexelizumab and infarct size in patients with acute myocardial infarction undergoing primary percutaneous coronary Intervention: a delayed enhancement cardiac magnetic resonance substudy from the APEX-AMI trial. JACC Cardiovasc Imaging 2010, 3:52-60.

75. Weir RA, Mark PB, Petrie CJ, Clements S, Steedman T, Ford I, Ng LL, Squire IB, Wagner GS, McMurray JJ, Dargie HJ: Left ventricular remodeling after acute myocardial infarction: does eplerenone have an effect? Am Heart J 2009, 157:1088-1096.

76. Tendera M, Wojakowski W, Ruzyllo W, Chojnowska L, Kepka C, Tracz W, Musialek P, Piwowarska W, Nessler J, Buszman P, et al: Intracoronary infusion of bone marrow-derived selected CD34+CXCR4+ cells and nonselected mononuclear cells in patients with acute STEMI and reduced left ventricular ejection fraction: results of randomized, multicentre Myocardial Regeneration by Intracoronary Infusion of Selected Population of Stem Cells in Acute Myocardial Infarction (REGENT) Trial. Eur Heart J 2009, 30:1313-1321.

77. Song YB, Hahn JY, Gwon HC, Kim JH, Lee SY, Choe YH, Choi SH, Choi JH, Lee SH: Upstream high-dose tirofiban does not reduce myocardial infarct size in patients undergoing primary percutaneous coronary intervention: a magnetic resonance imaging pilot study. Clin Cardiol 2009, 32:321-326.

78. Dill $T$, Schachinger $V$, Rolf A, Mollmann $S$, Thiele $H$, Tillmanns $H$, Assmus $B$, Dimmeler S, Zeiher AM, Hamm C: Intracoronary administration of bone marrow-derived progenitor cells improves left ventricular function in patients at risk for adverse remodeling after acute ST-segment elevation myocardial infarction: results of the Reinfusion of Enriched Progenitor cells And Infarct Remodeling in Acute Myocardial Infarction study (REPAIR-AMI) cardiac magnetic resonance imaging substudy. Am Heart J 2009, 157:541-547.

79. Atar D, Petzelbauer P, Schwitter J, Huber K, Rensing B, Kasprzak JD, Butter C, Grip L, Hansen PR, Suselbeck T, et al: Effect of intravenous FX06 as an adjunct to primary percutaneous coronary intervention for acute STsegment elevation myocardial infarction results of the F.I.R.E. (Efficacy of FX06 in the Prevention of Myocardial Reperfusion Injury) trial. J Am Coll Cardiol 2009, 53:720-729.

80. Hahn JY, Gwon HC, Choe YH, Rhee I, Choi SH, Choi JH, Lee SH, Hong KP, Park JE: Effects of balloon-based distal protection during primary percutaneous coronary intervention on early and late infarct size and left ventricular remodeling: a pilot study using serial contrast-enhanced magnetic resonance imaging. Am Heart J 2007, 153:665 e661-668.

81. Engelmann MG, Theiss HD, Hennig-Theiss C, Huber A, Wintersperger BJ, Werle-Ruedinger AE, Schoenberg SO, Steinbeck G, Franz WM: Autologous bone marrow stem cell mobilization induced by granulocyte colonystimulating factor after subacute ST-segment elevation myocardial infarction undergoing late revascularization: final results from the G-CSFSTEMI (Granulocyte Colony-Stimulating Factor ST-Segment Elevation Myocardial Infarction) trial. J Am Coll Cardiol 2006, 48:1712-1721.

82. Kang HJ, Lee HY, Na SH, Chang SA, Park KW, Kim HK, Kim SY, Chang HJ, Lee W, Kang WJ, et al: Differential effect of intracoronary infusion of mobilized peripheral blood stem cells by granulocyte colony-stimulating factor on left ventricular function and remodeling in patients with acute myocardial infarction versus old myocardial infarction: the MAGIC Cell-3DES randomized, controlled trial. Circulation 2006, 114:1145-151.

83. Ripa RS, Jorgensen E, Wang Y, Thune JJ, Nilsson JC, Sondergaard L, Johnsen HE, Kober L, Grande P, Kastrup J: Stem cell mobilization induced by subcutaneous granulocyte-colony stimulating factor to improve cardiac regeneration after acute ST-elevation myocardial infarction: result of the double-blind, randomized, placebo-controlled stem cells in myocardial infarction (STEMMI) trial. Circulation 2006, 113:1983-1992.

84. Janssens S, Dubois C, Bogaert J, Theunissen K, Deroose C, Desmet W, Kalantzi M, Herbots L, Sinnaeve P, Dens J, et al: Autologous bone marrowderived stem-cell transfer in patients with ST-segment elevation myocardial infarction: double-blind, randomised controlled trial. Lancet 2006, 367:113-121.

85. Thiele H, Engelmann L, Elsner K, Kappl MJ, Storch WH, Rahimi K, Hartmann A, Pfeiffer D, Kneissl GD, Schneider D, et al: Comparison of pre- 
hospital combination-fibrinolysis plus conventional care with prehospital combination-fibrinolysis plus facilitated percutaneous coronary intervention in acute myocardial infarction. Eur Heart J 2005, 26:1956-1963.

86. Wollert KC, Meyer GP, Lotz J, Ringes-Lichtenberg S, Lippolt P, Breidenbach C, Fichtner S, Korte T, Hornig B, Messinger D, et al: Intracoronary autologous bone-marrow cell transfer after myocardial infarction: the BOOST randomised controlled clinical trial. Lancet 2004, 364:141-148.

87. Darasz KH, Bayliss J, Underwood SR, Keegan J, Poole-Wilson PA, Sutton GC Left ventricular volume in thrombolysed patients with acute anterior myocardial infarction: the effect of captopril and xamoterol. Int I Cardiol 1995, 51:137-142.

doi:10.1186/1745-6215-12-204

Cite this article as: Desch et al:: Cardiac magnetic resonance imaging parameters as surrogate endpoints in clinical trials of acute myocardial infarction. Trials 2011 12:204.

\section{Submit your next manuscript to BioMed Central} and take full advantage of:

- Convenient online submission

- Thorough peer review

- No space constraints or color figure charges

- Immediate publication on acceptance

- Inclusion in PubMed, CAS, Scopus and Google Scholar

- Research which is freely available for redistribution

Submit your manuscript at www.biomedcentral.com/submit 